\title{
Leukocyte infection by the granulocytic ehrlichiosis agent is linked to expression of a selectin ligand
}

\author{
Jesse L. Goodman, ${ }^{1}$ Curtis M. Nelson, ${ }^{1}$ Marina B. Klein, ${ }^{1}$ Stanley F. Hayes, ${ }^{2}$ \\ and Brent W. Weston ${ }^{3}$

\begin{abstract}
${ }^{1}$ Department of Medicine, University of Minnesota School of Medicine, Minneapolis, Minnesota 55455, USA
${ }^{2}$ National Institutes of Health, Rocky Mountain Laboratory, Hamilton, Montana 59840, USA

${ }^{3}$ Department of Pediatrics, School of Medicine, University of North Carolina at Chapel Hill, Chapel Hill,
\end{abstract} \\ North Carolina 27599, USA
}

Address correspondence to: Jesse L. Goodman, Division of Infectious Diseases, Department of Medicine, University of Minnesota School of Medicine, 516 Delaware Street, Minneapolis, Minnesota 55455, USA. Phone: (612) 624-9996;

Fax: (612) 625-4410; E-mail: jgoodman@oc.fda.gov

Received for publication June 9, 1998, and accepted in revised form December 21, 1998.

\begin{abstract}
Human granulocytic ehrlichiosis (HGE) is an emerging tickborne illness caused by an intracellular bacterium that infects neutrophils. Cells susceptible to HGE express sialylated Lewis $\mathrm{x}$ (CD15s), a ligand for cell selectins. We demonstrate that adhesion of HGE to both HL60 cells and normal bone marrow cells directly correlates with their CD15s expression. HGE infection of HL60 cells, bone marrow progenitors, granulocytes, and monocytes was blocked by monoclonal antibodies against CD15s. However, these antibodies did not inhibit HGE binding, and anti-CD15s was capable of inhibiting the growth of HGE after its entry into the target cell. In contrast, neuraminidase treatment of HL60 cells prevented both HGE binding and infection. A cloned cell line (HL60-A2), derived from HL60 cells and resistant to HGE, was deficient in the expression of $\alpha-(1,3)$ fucosyltransferase (Fuc-TVII), an enzyme known to be required for $\mathrm{CD} 15 \mathrm{~s}$ biosynthesis. Less than $1 \%$ of HL60-A2 cells expressed CD15s, and only these rare CD15s-expressing cells bound HGE and became infected. After transfection with Fuc-TVII, cells regained CD15s expression, as well as their ability to bind HGE and become infected. Thus, CD15s expression is highly correlated with susceptibility to HGE, and it, and/or a closely related sialylated and $\alpha-(1,3)$ fucosylated molecule, plays a key role in HGE infection, an observation that may help explain the organism's tropism for leukocytes.
\end{abstract}

J. Clin. Invest. 103:407-412 (1999).

\section{Introduction}

Human granulocytic ehrlichiosis (HGE) is a newly recognized tickborne infection of humans (1-3). HGE is a febrile illness characterized by reductions in blood leukocyte and platelet counts and the presence of colonies of infecting organisms (morulae) proliferating within cytoplasmic vacuoles of circulating neutrophils. No other organism is known to replicate within human granulocytes. Our laboratory recently isolated and propagated the causative agent of this disease using the human promyelocytic leukemia cell line HL60 (4). In addition, we found that the agent can grow in primary bone marrow granulocytic and monocytic precursors, blood neutrophils, and nonactivated monocytes (5).

The clinical and in vitro tropism of this obligate intracellular parasite for myelomonocytic cells suggested that specific cell-surface molecules are required for adhesion, cell signaling, and entry into a permissive intracellular compartment. Of interest, sialyl Lewis x ([NeuAco(23)GalB1-4(Fuca1-3)GlcNAc, or CD15s]), which serves as a ligand to initially tether leukocytes to endothelial cell Eselectin $(6,7)$, is richly expressed on both HL60 cells and on those bone marrow and blood cells permissive for the HGE agent (8-11), where it modifies a variety of lipid and protein molecules. We hypothesized that cell-surface sialylated Lewis $\mathrm{x}$ might be important for infection by HGE.

\section{Methods}

HGE infection, cultivation, and antibody blocking studies. A cell-free bacterial inoculum of HGE was prepared from fully infected HL60 cells, propagated as described (4). The infected cells, at a density of $10^{6}$ per $\mathrm{ml}$, were passed through a 25 -gauge needle three times, and cellular debris were removed by centrifugation at $700 \mathrm{~g}$ for $5 \mathrm{~min}$. The supernatant was centrifuged at $1,236 \mathrm{~g}$ for $5 \mathrm{~min}$, and the resultant bacterial pellet was resuspended in $10 \mu \mathrm{l}$ supernatant per $\mathrm{ml}$ of the original culture. Counting in a Petroff-Hausser chamber revealed $\sim 10^{7}$ organisms per $10 \mu \mathrm{l}$. Infections were carried out by coincubating $10 \mu \mathrm{l}$ of this cell-free HGE preparation with $10^{6}$ cells for a multiplicity of infection of $\sim 10$ organisms per cell used in all experiments. For studies to determine whether bacterial binding requires calcium, both HL60 cells and the bacterial inoculum were separately incubated in HBSS with or without calcium for 20-70 min before coincubation, as described later here. For blocking studies, $10 \mu \mathrm{g}$ (or the quantity specified) of the monoclonal antibody (MAB) tested (or control diluent or murine IgM alone) was added to $1 \mathrm{ml}$ of $10^{6} \mathrm{HL} 60$ cells (or bone marrow progenitors, peripheral blood monocytes, or granulocytes, prepared as described; ref. 5) in medium and incubated at room temperature for $1 \mathrm{~h}$. Blocking studies were performed six times with similar results. As noted, antibody blocking studies were also performed at $4^{\circ} \mathrm{C}$ or $37^{\circ} \mathrm{C}$. Cells were centrifuged at $200 \mathrm{~g}$ for $5 \mathrm{~min}, 900 \mu \mathrm{l}$ of supernatant saved, the cells resuspended in the $100 \mu$ l of medium remaining, and $10 \mu \mathrm{l}$ of the HGE bacteria added and then coincubated for $15 \mathrm{~min}$ at room temperature. The cells were then washed and 
Table 1

$\alpha-(1,3)$ fucosyltransferase activity in cellular extracts

\begin{tabular}{lcc} 
Cell line & Acceptor & $\begin{array}{c}\text { Mean enzyme activity } \\
(\mathrm{pmol} / \mathrm{mg} / \mathrm{h} \pm \mathrm{SEM})\end{array}$ \\
HL60 & LacNac & $1085 \pm 93$ \\
HL60-A2 & Sialyl-LacNac & $364 \pm 25$ \\
& LacNac & $3334 \pm 176$ \\
HL60-A2C & Sialyl-LacNac & $21 \pm 8^{\mathrm{A}}$ \\
& LacNac & $787 \pm 60$ \\
& Sialyl-LacNac & $639 \pm 71$ \\
\hline
\end{tabular}

AP $<0.05$ vs. HL60 and HL60-A2C.

pelleted three times in growth medium and resuspended in the retained $900 \mu \mathrm{l}$ of medium containing the MAB. In experiments to determine the effects of anti-CD15s on bacteria that had already entered cells, $50 \mu \mathrm{g} / \mathrm{ml}$ of gentamicin was added to the cultures for a period of $1 \mathrm{~h}$, at time points from 4 to $18 \mathrm{~h}$ after incubation with bacteria. This procedure killed any remaining infectious extracellular organisms (data not shown), thus enabling assessment of the effects of antibody on intracellular organisms alone. Cells were incubated as described $(4,5)$ and assessed for infection (see later here) daily.

Monoclonal antibodies. The anti-CD15s antibody CSLEX1 (12) was obtained from Becton Dickinson Immunocytometry Systems (San Jose, California, USA); KM93 (13) from Kamiya Biomedical (Tukwila, Washington, USA); and 2H5 (14) and 2F3 (15) from PharMingen (San Diego, California, USA). VIM-2 (16) was obtained from BioSource International (Camarillo, California, USA). Control antibodies were kindly provided by Keith Skubitz (Division of Oncology, University of Minnesota).

Immunofluorescent and electron microscopy. For immunofluorescent detection of CD15s and/or HGE antigens, respectively, cytospin preparations of $10^{5}$ cells were fixed with methanol/acetone (1:1) and probed at room temperature for $1 \mathrm{~h}$ with CSLEX1 $(0.25 \mu \mathrm{g} / \mathrm{ml})$ or anti-HGE serum (diluted 1:200 from a culturepositive patient with an immunofluorescent antibody [IFA] titer of 1:5,120), each diluted in Tris-buffered saline with $3 \%$ BSA. Goat anti-mouse IgM was used as the second antibody to detect CD15s, and goat anti-human IgG was used to detect HGE antigens (both from Organon Teknika Corp., West Chester, Pennsylvania, USA). For electron microscopy, cells were prepared by pelleting at $94 \mathrm{~g}$ followed by resuspension in a phosphatebuffered fixative of $4 \%$ paraformaldehyde, $2.5 \%$ glutaraldehyde, and $0.1 \mathrm{M}$ sucrose ( $\mathrm{pH} 7.0$ ). The cells were embedded in agarose, postfixed with reduced osmium, and subjected to a mordanting process using tannic acid before embedding, sectioning, and staining with $\mathrm{KMnO}_{4}$ as described (17).

Neuraminidase treatment and evaluation of bacterial adhesion and infection. Neuraminidase Type X (Sigma Chemical Co., St. Louis,
Missouri, USA) was dissolved in $0.5 \mathrm{ml}$ of $0.15 \mathrm{M} \mathrm{NaCl}, 5 \mathrm{mM}$ $\mathrm{CaCl}_{2}$ ( $\mathrm{pH}$ 6.0) at the concentrations specified. HL60 cells $\left(10^{6}\right)$ were incubated in this buffer (with or without enzyme) at $37^{\circ} \mathrm{C}$ for $2 \mathrm{~h}$. Neuraminidase-treated and -untreated control cells were then washed in medium, pelleted, resuspended in $0.1 \mathrm{ml}$ of medium, and coincubated with $10 \mu \mathrm{l}$ of cell-free HGE prepared as described. For studying possible neuraminidase effects on organisms, $10^{7}$ identically neuraminidase-treated or untreated bacteria were coincubated with $10^{6} \mathrm{HL} 60$ cells. After $15 \mathrm{~min}$ at room temperature, cells were washed two times with $5 \mathrm{ml}$ of medium to remove unbound bacteria. Cytospin slides were prepared for indirect immunofluorescence microscopy to evaluate bacterial adhesion and, at later time points, stained with Giemsa to evaluate the development of infection. Bacterial binding was quantitated by an observer blinded as to experimental group, counting rhodamine-labeled HGE organisms adherent to the surface of each of at least 100 cells per experimental group. Similarly, infection (and blocking) was quantitated by determining, in each experimental group, the percentage of 100 cells showing visible morula(e) at the indicated time points. The statistical difference in adhesion and/or infection was compared among experimental groups using two-tailed $t$ tests and $\chi^{2}$ analysis, respectively, utilizing Microsoft Excel software (Microsoft Corp., Redmond, Washington, USA).

Selection and characterization of a cloned HGE-resistant HL60 subline. HL60 cells were infected with the human isolate HGE-1 as described (4). After infection, rare surviving cells were removed and grown in the absence of the organism. The cell population was then cloned twice by limiting dilution in 96-well plates, and the cloned uninfected subline (HL60-A2) was again challenged with HGE and found to be resistant to infection. FACS (Becton Dickinson Immunocytometry Systems) analysis for relevant cell-surface antigens was performed using standard methods and antibodies (18).

Fucosyltransferase assays. Cell extracts containing 1\% Triton X100 were prepared from HL60, HL60-A2, and HL60-A2C cells as described (19). Fucosyltransferase assays were performed in a volume of $20 \mu \mathrm{l}$ and contained $25 \mathrm{mM}$ sodium cacodylate $(\mathrm{pH}$ 6.2), $5 \mathrm{mM}$ ATP, $10 \mathrm{mM}$ L-fucose, $20 \mathrm{mM} \mathrm{MnCl}_{2}, 3 \mu \mathrm{M}$ GDP$\left[{ }^{14} \mathrm{C}\right]$ fucose, and $10 \mu \mathrm{g}$ of cell-extract protein. The acceptor substrate ( $N$-acetyllactosamine, Gal $\beta 1 \rightarrow 4 \mathrm{GlcN}$ Ac) was added to a final concentration of $20 \mathrm{mM}$. Control assays with no added acceptor were performed using the same conditions. Reactions were incubated at $37^{\circ} \mathrm{C}$ for $1 \mathrm{~h}$.

Terminated assays were centrifuged and the supernatants were collected. An aliquot of each supernatant was subjected to scintillation counting. Another aliquot was applied to a column containing Dowex 1X2-400 in the formate form. To quantitate incorporation of radioactive fucose into product, the flow-through fraction and $2 \mathrm{ml}$ of a subsequent water elution were collected and counted. Amine-adsorption HPLC was used to confirm the structure of the product formed as described previously (19). For fucosyltransferase assays using $\alpha-(2,3)$ sia-
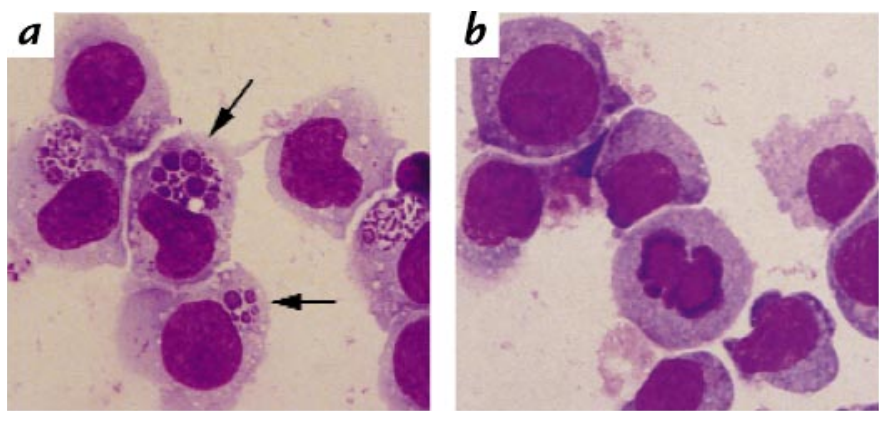

\section{Figure 1}

Anti-CD15s antibody blocks infection of HL60 cells by the HGE agent. HL60 cells 3 days after incubation with the HGE agent in the absence $(\boldsymbol{a})$ or presence $(\boldsymbol{b})$ of MAB against CD15s (CSLEX1; 10 $\mu \mathrm{g} / \mathrm{ml}$ ). a shows typical intracellular organisms (arrows) that are absent in the antibody-treated cells $(b)$. HGE, human granulocytic ehrlichiosis; $M A B$, monoclonal antibody. 
Table 2

FACS analysis of relevant cell-surface antigens on cell lines studied

$\begin{array}{lcc}\text { Cell line } & \text { Antigen } & \text { Mean fluorescence intensity } \\ \text { HL60 } & \text { Lewis } x & 610 \\ & \text { Sialyl Lewis } x & 2895 \\ \text { HL60-A2 } & \text { VIM-2 } & 105 \\ & \text { Lewis x } & 1270 \\ & \text { Sialyl Lewis x } & 13^{\mathrm{B}} \\ \text { HL60-A2C } & \text { VIM-2 } & 301 \\ & \text { Lewis x } & 1189 \\ & \text { Sialyl Lewis x } & 3110 \\ & \text { VIM-2 } & 88\end{array}$

${ }^{A}$ Negative control antibodies (mouse $\lg \mathrm{G} 1 / \lg \mathrm{g} 2$ ) mean fluorescence index $<10$. ${ }^{B} P<0.05$ HL60-A2 vs. HL60 or HL60A2C.

lyl- $N$-acetyllactosamine (NeuNAc $\alpha 2 \rightarrow 3 \mathrm{Gal} \beta 1 \rightarrow 4 \mathrm{GlcN}$ Ac; Oxford GlycoSystems Inc., Jamaica, New York, USA) as the substrate, terminated assays were centrifuged and the supernatants were collected. A $200-\mu \mathrm{l}$ aliquot of this material was subjected to scintillation counting to determine the total amount of radioactivity in the diluted assay. A second $200-\mu$ laliquot was applied to a Dowex 1-X8 $\left(\mathrm{PO}_{4}{ }^{2-}\right)$ column. The flow-through fraction and three separate $1-\mathrm{ml}$ water elutions were collected and pooled, and an aliquot of this material was counted as a measure of product formation (19).

Reconstitution of Fuc-TVII and CD15s expression to the CD15sdeficient HL60-A2 cells. The plasmids pcDNA3-FUT7 (Fuc-TVII coding region cloned downstream of the human cytomegalovirus (CMV) immediate early promoter in the EcoRI site of pcDNA3 [Invitrogen Corp., Carlsbad, California, USA]) and pcDNA3-CAT (chloramphenicol acetyl transferase [CAT] coding region cloned into the HindIII site), were linearized with PvuI and cotransfected into HL60-A2 cells as described (20). Transfected cells were maintained in fresh medium containing $200 \mu \mathrm{g} / \mathrm{ml}$ of G418 (Geneticin; GIBCO BRL, Grand Island, New York, USA). After 3 weeks in G418, viable cells were cloned by limiting dilution in 96-well plates. Positive cells were selected if they expressed both CD15s (assayed by FACS) and CAT (assayed enzymatically as described in ref. 21). A CD15sand CAT-expressing clone, HL60-A2C, was maintained in medium without antibiotics for 1 week before challenge with the HGE agent. Binding and infection assays were performed as described for HL60-A2 cells.

\section{Results}

We first determined whether MABs directed against CD15s would affect HGE infection of HL60 cells. After treatment with $10 \mu \mathrm{g} / \mathrm{ml}$ of any of four different antiCD15s MABs (CSLEX1, KM93, 2H5, and 2F3), only $0 \%-1 \%$ of HL60 cells contained morulae $3-5$ days after inoculation vs. $30 \%-95 \%$ of cells (range among six experiments) infected in the absence of anti-CD15s or with control MABs of the same (IgM) isotype (Fig. 1, $a$ and $b$; $P<$ 0.001 , controls vs. anti-CD $15 \mathrm{~s})$. Concentrations of CSLEX1 or KM93 as low as $2.5-5 \mu \mathrm{g} / \mathrm{ml}$, respectively, completely prevented infection of HL60 cells (Fig. 2). The VIM-2 MAB, directed against the closely related sialylated CDw65 carbohydrate moiety, had irregular blocking activity noted only at the highest concentration tested (40 $\mu \mathrm{g} / \mathrm{ml}$ ), with a maximal reduction in infection to $60 \%$ of the level seen in untreated controls, suggesting either non- specific effects or biologic cross-reactivity of high concentrations of VIM-2 against CD15s (22). Anti-CD15s antibody was also tested for its ability to block infection of those nontransformed cells likely to be natural targets of the HGE agent: human marrow progenitors and peripheral blood monocytes and granulocytes (5). As observed in HL60 cells, $10 \mu \mathrm{g} / \mathrm{ml}$ of MAB CSLEX1 prevented infection of all of these cell types ( $P<0.001$ vs. untreated controls).

In contrast to the protective effects of anti-CD15s, MABs directed against nonsialylated CD15 (SSEA-1, AHN 1, and AHN 1.1), against leukocyte activation markers CD66 (CD66-1 and 14) and CD67 (AHN-16), and against the CD18 $\beta$-integrin subunit (60.3) had no effect on infection. The inhibition of HGE infection by anti-CD15s occurred whether infection was carried out using infected HL60 cells or cell-free bacteria as the inoculum. Preincubation of the bacterial inoculum (rather than the target cells) with CSLEX1 $(10 \mu \mathrm{g} / \mathrm{ml}$ for 1 hour at $37^{\circ} \mathrm{C}$ ) did not prevent infection, nor did CSLEX1 bind to isolated bacteria.

Functional binding by CD15s to its normal receptors, the selectins, depends on the presence of its terminal sialic acid and is eliminated by treatment with neuraminidase (23). We therefore tested whether neuraminidase treatment of HL60 cells would affect the HGE agent's ability to bind to and infect them. Although more than $95 \%$ of control untreated cells became infected, pretreatment with $0.15-1.5 \mathrm{U} / \mathrm{ml}$ of neuraminidase, but not lower concentrations, completely prevented infection $(P<0.001)$. In addition, neuraminidase treatment eliminated specific HGE binding to the HL60 cell surface (Fig. 3; $0.2 \pm 0.4$ bound bacteria per cell after neuraminidase treatment vs. $2.5 \pm 2.3$ bacteria bound per untreated cell; $P<0.001)$. Conversely, neuraminidase treatment of purified HGE did not result in any loss of either bacterial binding or infectivity.

Given that the binding of lectins to cell-surface carbohydrates such as CD15s is a calcium-dependent process, we sought to determine whether HGE binding is calcium-dependent. In these studies, organisms and cells were separately preincubated for 20 or 70 minutes in Hanks' balanced salt solution (HBSS), either with or without calcium, before infection. Binding to HL60 cells

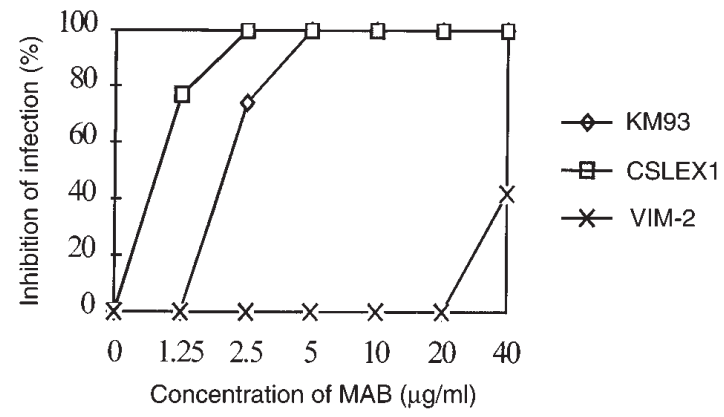

Figure 2

Dose-response curve of inhibition of HGE infection of HL60 cells by treatment of cells with anti-CD15s antibodies CSLEX1 (squares) and KM93 (diamonds), and with anti-CDw65 (VIM-2, x marks). Percent of inhibition given is the reduction in the percentage of cells infected $72 \mathrm{~h}$ after inoculation with HGE compared with control cells coincubated with control IgM. 

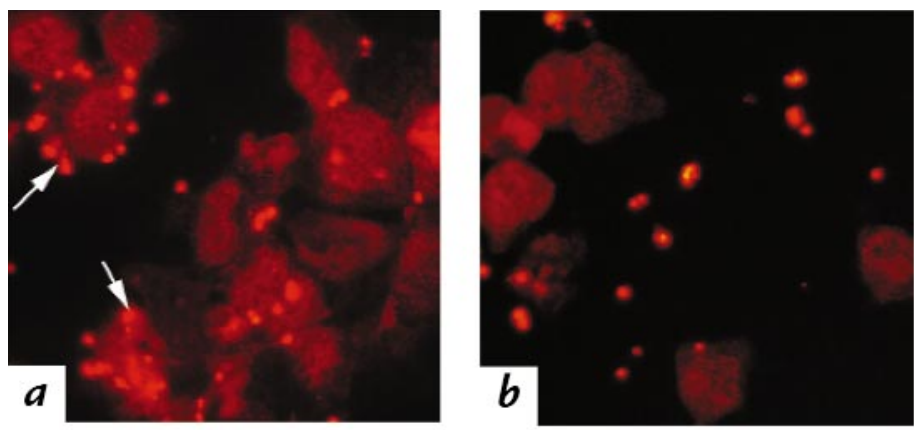

Figure 3

Neuraminidase pretreatment inhibits HGE adhesion to HL60 cells. Specific cell-surface binding of rhodamine-labeled HGE organisms (arrows) is present in untreated HL60 cells ( $a$ ) but absent in cells pretreated with neuraminidase $(\boldsymbol{b})$.

was not calcium-dependent (e.g., mean $3.4 \pm 2.9$ vs. 3.64 \pm 2.8 bacteria bound per cell after 70 minutes without or with calcium, respectively; $P=0.5$ ).

To determine whether anti-CD15s antibodies, like neuraminidase treatment, block bacterial binding, HL60 cells were pretreated with CSLEX1 or the other antiCD15s MABs $(10 \mu \mathrm{g} / \mathrm{ml})$ for 1 hour at $4^{\circ} \mathrm{C}-37^{\circ} \mathrm{C}$, and then bacteria were added for 15 minutes at $4^{\circ} \mathrm{C}$ (to examine adhesion) or $37^{\circ} \mathrm{C}$ (to allow entry), followed by observation immediately, and 2 and 4 hours later, using indirect immunofluorescence and electron microscopy. No difference was noted in bacterial adhesion between MAB-treated (whether at $4^{\circ} \mathrm{C}, 20^{\circ} \mathrm{C}$, or $37^{\circ} \mathrm{C}$ ) and -untreated cells. However, by electron microscopy, fewer CSLEX1-treated cells (1\%-2\%) had intracellular organisms noted at 2-4 hours after infection compared with untreated cells $(6 \%-20 \% ; P<0.05)$. In addition, by four hours after infection, approximately half of those bacteria seen within anti-CD15s-treated cells, but none of those within control untreated cells, were noted to be undergoing degeneration. By 24 hours, any organisms that had entered the MAB-treated cells appeared to have failed to move further into the cell's interior and did not multiply or develop beyond the ingestion stage.

Given these findings, we sought to determine whether late treatment of cells with anti-CD15s, after bacterial entry, could affect the fate of intracellular organisms. For these experiments, cells were infected with HGE as described, and gentamicin added for a period of 1 hour, at either 4 or 18 hours after infection, to kill any organisms that had not already entered the cell. CSLEX1 was then added. When examined 72 hours after infection, $48 \%-57 \%$ of cells that had been treated with CSLEX 1 were infected vs. $77 \%-80 \%$ of control untreated cells (for each of two experiments, $P<0.05$ ). In addition, the vacuoles in CSLEX1-treated cells contained fewer organisms, and those organisms present often appeared to be damaged and degenerating. Identical results were obtained when MAB $2 \mathrm{H} 5$ was used as the postentry treatment.

An HGE-resistant HL60 cell line, HL60-A2, was cloned from cells surviving previous infection. These cells have no HGE present by IFA and are noninfectious when added to other HL60 cells. By both FACS analysis and IFA, HL60-A2 expresses CD15s on only $<1 \%$ of cells but expresses other sialylated surface molecules (e.g., CDw65) normally. There is no evidence that HL60-A2 cells are activated based on comparison with parental HL60 cells of surface expression of CR3 (CD11b/CD18) and LFA-1 (CD11a/CD18) or based on superoxide production and granule markers in response to the agonists FMLP and PMA (24). Biochemical analysis revealed that HL60-A2 cells have a defect in the expression of enzymatic activity consistent with the $\alpha-(1,3)$ fucosyltransferase enzyme FucTVII, responsible for the terminal fucosylation of CD15s (25). This is indicated by their greatly reduced ability to terminally fucosylate sialyl-LacNac compared with parental HL60 cells, in contrast to their normal fucosylation of nonsialylated LacNac (Table 1). In addition, we have recently shown that there is a marked reduction in the level of transcription of the Fuc-TVII gene in HL60A2 cells, which also fail to adhere normally to cytokinestimulated endothelial cells. Inoculation of this cloned subline with HGE ultimately resulted in infection of $<1 \%$ of the cells (vs. 99\% of parental HL60 cells; $P<0.001$ ). Dual immunofluorescence with anti-HGE serum and anti-CD15s (CSLEX1) revealed that, unlike the normal CD15s-expressing parental HL60 cells that uniformly bind bacteria (Fig. $4 a$; mean $3.8 \pm 2.4$ bacteria per cell) and become infected (Fig. 4b), the HL60-A2 cells only bound a mean of $0.03 \pm 0.2$ bacteria per cell (Fig. $4 c ; P<0.001$ ) and subsequently infected (Fig. $4 d$ ) only the rare CD15sexpressing cells present in the HL60-A2 line.

We next determined whether reconstitution of CD15s expression to HL60-A2 cells would result in restoration of HGE binding and cellular susceptibility to infection. HL60-A2 cells were transfected with an expression plasmid containing the FucT-VII and CAT coding regions and were selected for neomycin resistance. Cloned transfectants were assayed for CD15s expression, $\alpha$ - $(1,3)$ fucosyltransferase and CAT activity. A CD15s-positive cell line, HL60-A2C, derived from these selections, and the original CD15s-negative HL60-A2 cells were then challenged with HGE. Unlike HL60-A2 cells, the FucT-VII-transfected HL60-A2C cells (but not transfection controls) all exhibited high-level CD15s expression, bound the HGE bacterium avidly (Fig. $4 e$; mean $3.5 \pm 3.4$ bacteria per cell; $P<$ 0.001 vs. HL60-A2 cells), and became infected (Fig. 4f). Results of FACS analyses (Table 2) confirm the marked deficiency of CD15s expression in HL60-A2 cells (despite normal CD15 and VIM-2 expression) and the reconstitution of CD15s expression in HL60-A2C cells.

Cultured CD $34^{+}$, HLA-DR ${ }^{+}$normal human bone marrow cells, which we have shown are susceptible to infection with HGE (5), contain an evolving population of cells with variable CD15s expression. To determine whether bacterial adhesion to these cells correlates with their CD15s expression, we performed dual immunofluorescence studies of maximally susceptible 4-day-old bone marrow pro- 
genitor cultures inoculated with HGE. Individual cells were first characterized by fluorescein CSLEX1 labeling into high, intermediate, or low-null expressors of CD15s, and the bacteria bound to each cell then enumerated under rhodamine visualization. The binding of HGE to the cell surface directly correlated with CD15s expression. High expressors of CD15s bound a mean of 3.66 bacteria per cell vs. 1.70 for intermediate and 0.63 for low-null expressors $(P<0.05$ for all comparisons). Finally, we similarly determined whether the binding of HGE to HL60 cells also correlates with the expression of CD15s by individual cells, which is heterogeneous in low-passage HL60 cultures. Indeed, we found that those wild-type HL60 cells that did not visibly express CD15s seldom bind HGE (mean $0.0 \pm 0.0$ bound bacteria per cell), whereas normal CD15s-expressing cells avidly bound the bacterium (mean $5.5 \pm 3.6$ bacteria per cell; $P<0.0001$ vs. nonexpressors).

\section{Discussion}

The data presented demonstrate that CD15s and/or a very closely related sialylated and Fuc-TVII $\alpha-(1,3)$ fuco-
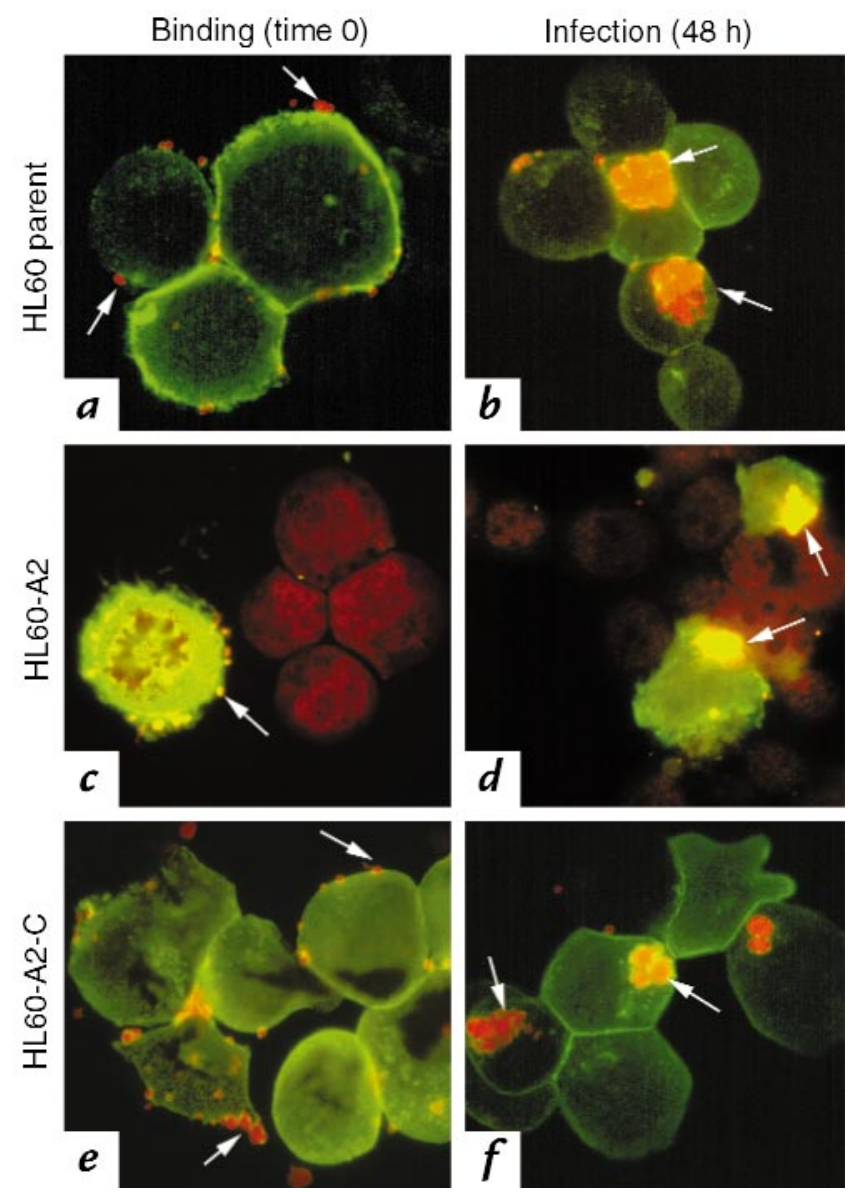

Figure 4

CD15s expression correlates with HGE adhesion to, and infection of, HL60 cells. Photomicrographs of HGE antigens (rhodamine-labeled) and CD15s expression (fluorescein-labeled) illustrating HGE binding to (time 0 ) and infection of (48 h): HL60 parent cells ( $\boldsymbol{a}$ and $\boldsymbol{b}$ ); the HGE-resistant, CD15s-deficient cell line, HL60-A2 ( $\boldsymbol{c}$ and $\boldsymbol{d}$; fields selected to show rare CD15s-expressing cells); and the CD15s-expressing Fuc-TVII transfectant derivative, HL60-A2C ( $\boldsymbol{e}$ and $\boldsymbol{f}$ ). Typical bacterial adhesion and intracellular colonies (arrows) are only observed in CD15s-expressing cells. sylated molecule plays a critical role in the infection of human hematopoietic cells by the HGE agent. Infection of (but not binding to) susceptible cell types is blocked by MABs against CD15s, and neuraminidase treatment of cells abolishes bacterial binding and infection. HGE binding to both HL60 cells and bone marrow progenitors correlates directly with their surface CD15s expression. Finally, an HGE-resistant subline of HL60 cells, which fails to bind HGE or become infected, is deficient in the transcription and enzymatic activity of the FucTVII fucosyltransferase responsible for CD15s synthesis. Genetic reconstitution of $\mathrm{CD} 15 \mathrm{~s}$ expression restores these cells' abilities to bind HGE and become infected. All of these findings support an important role of CD15s and/or a closely related molecule in HGE infection, possibly as a receptor component.

Although cell-surface CD15s was required for adhesion of HGE to HL60 cells, it is notable that MABs against CD15s, while preventing infection, did not prevent HGE binding or entry. Thus, anti-CD15s MABs may not be directed against the CD15s HGE-binding domain. The CD15s carbohydrate itself is present on $>10^{7}$ molecules per cell. Its underlying carbohydrate scaffolding varies in length and branching, and CD15s modifies many different proteins and sphingolipids $(26,27)$. Significant differences in biologic function can occur based on variations in this scaffolding, and anti-CD15s MABs may not be capable of fully blocking binding to all of these moieties.

Alternatively, or in addition, the binding of HGE and/or other ligands to specific CD15s-modified surface proteins could lead to specific cell-signaling events (28, 29) and to endocytosis into an intracellular compartment supportive of the agent's growth. Therefore, anti-CD15s antibodies could prevent HGE infection without altering binding by affecting receptor conformation and/or by triggering a change in the nature of cell entry, activation, and/or endosomal trafficking or biochemistry. That antiCD15s MABs may act in such an indirect manner is suggested by the significant attenuation of infection noted even when antibody is added after bacterial entry. Finally, the very close correlation of CD15s expression with HGE binding and infection, but the failure of antibodies to block binding, could be explained by the possibility that a very closely related sialylated, as well as $\alpha-(1,3)$ fucosylated, molecule, whose expression is also controlled by Fuc-TVII, may be a key receptor component. The existence of such CD15s-coexpressed molecules has been postulated as an explanation for otherwise unexplained discrepancies noted in some instances between cellular CD15s expression and binding to selectin ligands (30).

This is the first pathogen shown to involve CD15s in cellular infection. CD15s, although present on many transformed cells, is expressed primarily on blood and bone marrow leukocytes, the cellular targets of HGE both in vitro and in vivo. Our findings may explain, at least in part, the organism's unique cellular tropism. The agent's interactions with cell-surface CD15s may also affect disease pathogenesis in less direct ways than by simply targeting infection to permissive cells. These interactions could alter subsequent leukocyte binding to the selectin ligands for CD15s expressed on platelets, endothelium, and other leukocytes. Such interactions may be important in the 
trafficking of this intracellular organism through the bone marrow and the periphery and could evoke cell adhesion-dependent disease manifestations (31-35). Structurally similar carbohydrates have been previously implicated in the pathogenesis of infection by other agents. For example, nonsialylated Lewis $\mathrm{x}$ is expressed on the surface of Schistosoma mansonii, and cell-surface expression of Lewis $b$ has been implicated in the binding of Helicobacter pylori to gastric mucosal cells $(36,37)$.

The identification of specific CD15s-modified cellsurface molecule(s) and/or associated or biochemically related receptor components that interact with the HGE agent and, conversely, of the HGE molecule(s) that interact with these sialylated and Fuc-TVII fucosylated molecules, should define potential targets for the prevention and treatment of infection. In addition, further studies of the role of related cell-signaling events in the cellular pathogenesis and outcome of infection should provide insight into the unique abilities of this agent to enter and then proliferate within highly armed phagocytic cells.

\section{Acknowledgments}

Keith Skubitz and Margaret Hostetter provided helpful comments. We thank K. Bendt for technical assistance, J.M. Wiley for support, and M. Hayes for help preparing the manuscript. Supported by grants from National Institutes of Health-National Institute of Allergy and Infectious Diseases (1RO1AI40952-01 and 5RO1-AI37772-07 to J.L. Goodman).

1. Bakken, S., et al. 1994. Human granulocytic ehrlichiosis in the upper midwest United States. A new species emerging? JAMA. 272:212-218.

2. Chen, S.M., Dumler, J.S., Bakken, J.S., and Walker, D.H. 1994. Identification of a granulocytotropic Ehrlichia species as the etiologic agent of human disease. J. Clin. Microbiol. 32:589-595.

3. Anonymous. 1995. Granulocytic ehrlichiosis-New York, 1995. Morb. Mortal. Wkly. Rep. 44:593-595.

4. Goodman, J.L., et al. 1996. Direct cultivation of the causative agent of human granulocytic ehrlichiosis. N. Engl. J. Med. 334:209-215.

5. Klein, M.B., Miller, J.S., Nelson, C.M., and Goodman, J.L. 1997. Primary bone marrow progenitors of both granulocytic and monocytic lineages are susceptible to infection with the agent of human granulocytic ehrlichiosis. J. Infect. Dis. 176:1405-1409.

6. Phillips, M.L., et al. 1990. ELAM-1 mediates cell adhesion by recognition of a carbohydrate ligand, sialyl-Le ${ }^{x}$. Science. 250:1130-1132.

7. Walz, G., Aruffo, A., Kolanus, W., Bevilacqua, M., and Seed, B. 1990. Recognition of ELAM 1 of the sialyl-Le ${ }^{x}$ determinant on myeloid and tumor cells. Science. 250:1132-1135.

8. Fukuda, M., Spooncer, E., Oates, J.E., Dell, A., and Klock, J.D. 1984. Structure of sialylated fucosyl lactosaminoglycan isolated from human granulocytes. J. Biol. Chem. 259:10925-10935.

9. Munro, J.M., et al. 1992. Expression of sialyl-Lewis X, an E-selectin ligand, in inflammation, immune processes, and lymphoid tissues. Am.J. Pathol. 141:1397-1408.

10. Karakantza, M., et al. 1994. SLEx expression of normal CD34 positive bone marrow haemopoietic progenitor cells. Br. J. Haematol. 86:883-886.

11. Symington, F.W., Hedges, D.L., and Hakamori, S. 1985. Glycolipid antigens of human polymorphonuclear neutrophils and the inducible HL60 myeloid leukemia line. J. Immunol. 134:2498-2506.

12. Fukushima, K., et al. 1984. Characterization of sialosylated Lewis $\mathrm{x}$ as a new tumor-associated antigen. Cancer Res. 44:5279-5285.
13. Shitara, K., Hanai, N., and Yoshida, H. 1987. Distribution of lung adenocarcinoma-associated antigens in human tissues and sera defined by monoclonal antibodies KM-52 and KM-93. Cancer Res. 47:1267-1272.

14. Sawada, M., et al. 1993. Specific expression of a complex sialyl Lewis $x$ antigen on high endothelial venules of human lymph nodes: possible candidate for L-selectin ligand. Biochem. Biophys. Res. Commun. 193:337-347.

15. Ohmori, K., et al. 1993. A distinct type of sialyl Lewis X antigen defined by a novel monoclonal antibody is selectively expressed on helper memory T cells. Blood. 82:2797-2805.

16. Stockinger, H. 1989. Cluster report CDw65. In Leukocyte typing: white cell differentiation antigens. IV. W. Knapp, editor. Oxford University Press. New York, NY. 836-838.

17. Munderloh, U.G., et al. 1996. Isolation of the equine granulocytic ehrlichiosis agent, Ebrlichia equi, in tick cell culture. J. Clin. Microbiol. 34:664-670

18. Weston, B.W., Smith, P.L., Kelly, R.J., and Lowe, J.B. 1992. Molecular cloning of a fourth member of a human alpha $(1,3)$ fucosyltransferase gene family. Multiple homologous sequences that determine expression of the Lewis $x$, sialyl Lewis $x$, and difucosyl sialyl Lewis $x$ epitopes. J. Biol. Chem. 267:24575-24584.

19. Weston, B.W., Nair, R.P., Larsen, R.D., and Lowe, J.B. 1992. Isolation of a novel human alpha $(1,3)$ fucosyltransferase gene and molecular comparison to the human Lewis blood group alpha $(1,3 / 1,4)$ fucosyltransferase gene. Synthetic, homologous, nonallelic genes encoding enzymes with distinct acceptor substrate specificities. J. Biol. Chem. 267:4152-4160.

20. Baum, C., Forster, P., Hegewisch-Becker, S. and Harbers, K. 1994. An optimized electroporation protocol applicable to a wide range of cell lines. Biotechniques. 17:1058-1062.

21. Mollicone, R., et al. 1994. Molecular basis for plasma alpha (1,3)-fucosyltransferase gene deficiency (FUT6). J. Biol. Chem. 269:12662-12671.

22. Knibbs, R.N., et al. 1996. The fucosyltransferase FucT-VII regulates Eselectin ligand synthesis in human T cells. J. Cell. Biol. 133:911-920.

23. Polley, M.J., et al. 1991. CD62 and endothelial cell-leukocyte adhesion molecule 1 (ELAM-1) recognize the same carbohydrate ligand, sialylLewis x. Proc. Natl. Acad. Sci. USA. 88:6224-6228.

24. Weston, B.W., et al. 1991. Severe congenital neutropenia: clinical effects and neutrophil function during treatment with granulocyte colonystimulating factor. J. Lab. Clin. Med. 117:282-290.

25. Natsuka, S., Gersten, K., Zenita, K., Kannagi, R., and Lowe, J.B. 1994. Molecular cloning of a cDNA encoding a novel human leukocyte $\alpha-1,3$ fucosyltransferase capable of synthesizing the sialyl Lewis $\mathrm{x}$ determinant. J. Biol. Chem. 269:16789-16794.

26. Cooling, L.L., Zhang, D., and Koerner, T.A.W. 1997. Lewis $\mathrm{x}$ and sialyl $\mathrm{x}$ glycosphingolipids. Trends in Glycoscience and Glycotechnology. 9:191-208.

27. Bevilacqua, M.P. 1993. Endothelial-leukocyte adhesion on molecules. Annu. Rev. Immunol. 11:767-804.

28. Lund-Johansen, F., et al. 1992. Activation of human phagocytes through carbohydrate antigens (CD15, sialyl-CD15, CDw17, and CDw65). J. Immunol. 148:3221-3229.

29. Nagata K., et al. 1993. Activated platelets induce superoxide anion release by monocytes and neutrophils through P-selectin (CD62). J. Immunol. 151:3267-3273.

30. Kansas, G.S. 1996. Selectins and their ligands: current concepts and controversies. Blood. 88:3259-3287.

31. Bevilacqua, M.P., and Nelson, R.M. 1993. Selectins. J. Clin. Invest. 91:379-387. 32. Vaporciyan, A.A., et al. 1993. Involvement of platelet-endothelial cell adhesion molecule-1 in neutrophil recruitment in vivo. Science. 262:1580-1582.

33. Donnelly, S.C., et al. 1994. Role of selectins in development of adult respiratory distress syndrome. Lancet. 344: 215-219.

34. Mulligan, M.S., et al. 1992. Neutrophil-dependent acute lung injury. Requirement for P-selectin. J. Clin. Invest. 90:1600-1607.

35. Seekamp, A.N., et al. 1994. Role of selectins in local and remote tissue injury following ischemia and reperfusion. Am. J. Pathol. 144:592-598.

36. Srivatsan, J., Smith, D.F., and Cummings, R.D. 1992. The human blood fluke Schistosoma mansoni synthesizes glycoproteins containing the Lewis $\mathrm{x}$ antigen. J. Biol. Chem. 267:20196-20203.

37. Boren, T., Falk, P., Roth, K.A., Larson, G., and Normark, S. 1993. Attachment of Helicobacter pylori to human gastric epithelium mediated by blood group antigens. Science. 262:1892-1895. 